\title{
Dental management in transplant patients
}

\author{
Laura Carlos Fabuel ${ }^{1}$, Carmen Gavaldá Esteve ${ }^{2}, M^{\mathrm{a}}$ Gracia Sarrión Pérez ${ }^{1}$ \\ ${ }^{1}$ Dentist. \\ ${ }^{2}$ Staff physician, Service of Stomatology, Valencia University General Hospital.
}

Correspondence:

c/Tenor Garcia Romero, numero 5 pta 21

46015 Valencia

lauracarlosf@gmail.com

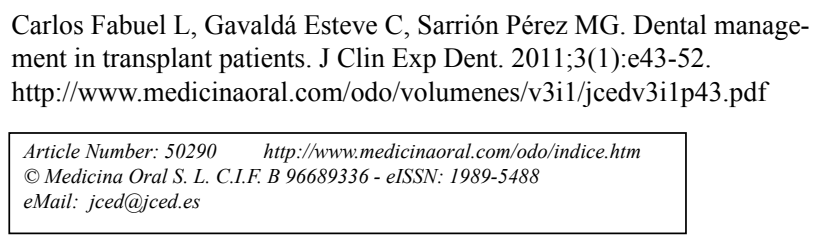

\begin{abstract}
Introduction: Transplant is the replacement with therapeutic purposes, of organs, tissues or cellular material for others, from a donor who is usually a human, alive or dead. In recent years, transplant organs have been developed by the advances that have occurred with immunosuppressive drugs and medical-surgical technology. Due to the frequency of transplants that are performed today, it is common to find these patients in dental clinics.

Objectives: To review the literature on oral manifestations in transplant patients and general dental management and according to transplant organs (heart, lung, liver, kidney, pancreas and bone marrow).

Material and Methods: For the literature review, we carried out a search in Pubmed / Medline database using limits and keywords according to the controlled vocabulary "Medical Subject Headings" (MeSH). We obtained a total of 30 articles (eight literature reviews, three randomized clinical trials, one cohort study, three case-control studies, eight clinical case series and seven cross-sectional studies).

Results and discussion: We describe the most common oral manifestations in transplant patients (viral, bacterial and fungal infections, gingival enlargement secondary to drug therapy and higher risk in the development of oral malignancy) and the special dental management that should be carried out on these patients, generally and specifically according to the type of transplant.
\end{abstract}

Key words: Transplant organs, dental management, oral manifestations. 


\section{Introduction}

We recognize as transplant the replacement, for therapeutic purposes, of organs, tissue or cellular material, other from a donor who is usually a human being, alive or dead. Transplant organs have been developed in recent years thanks to advances that have occurred with immunosuppressive drugs and medical-surgical techno$\operatorname{logy}(1,2)$. Due to the frequency of transplants that are performed actually, it is common to find these patients in dental clinics, therefore the dentist must understand the special dental management that should be carried out on these patients.
Transplants have been classified in different ways, one of them is by source: autograft or autologous, is derived from the individual's own (skin and bone marrow); syngeneic or isograft, donors and recipients are identical twins or homozygous; allograft or allogeneic donors and recipients are of the same species but genetically different; xenogeneic or xenograft, donors are from different species, and finally, from the umbilical cord.

Before a transplant has been performed you have to evaluate the immune status of the recipient to prevent rejection of the graft. Figure 1 summarizes the immune components involved in the mechanism of immune re-

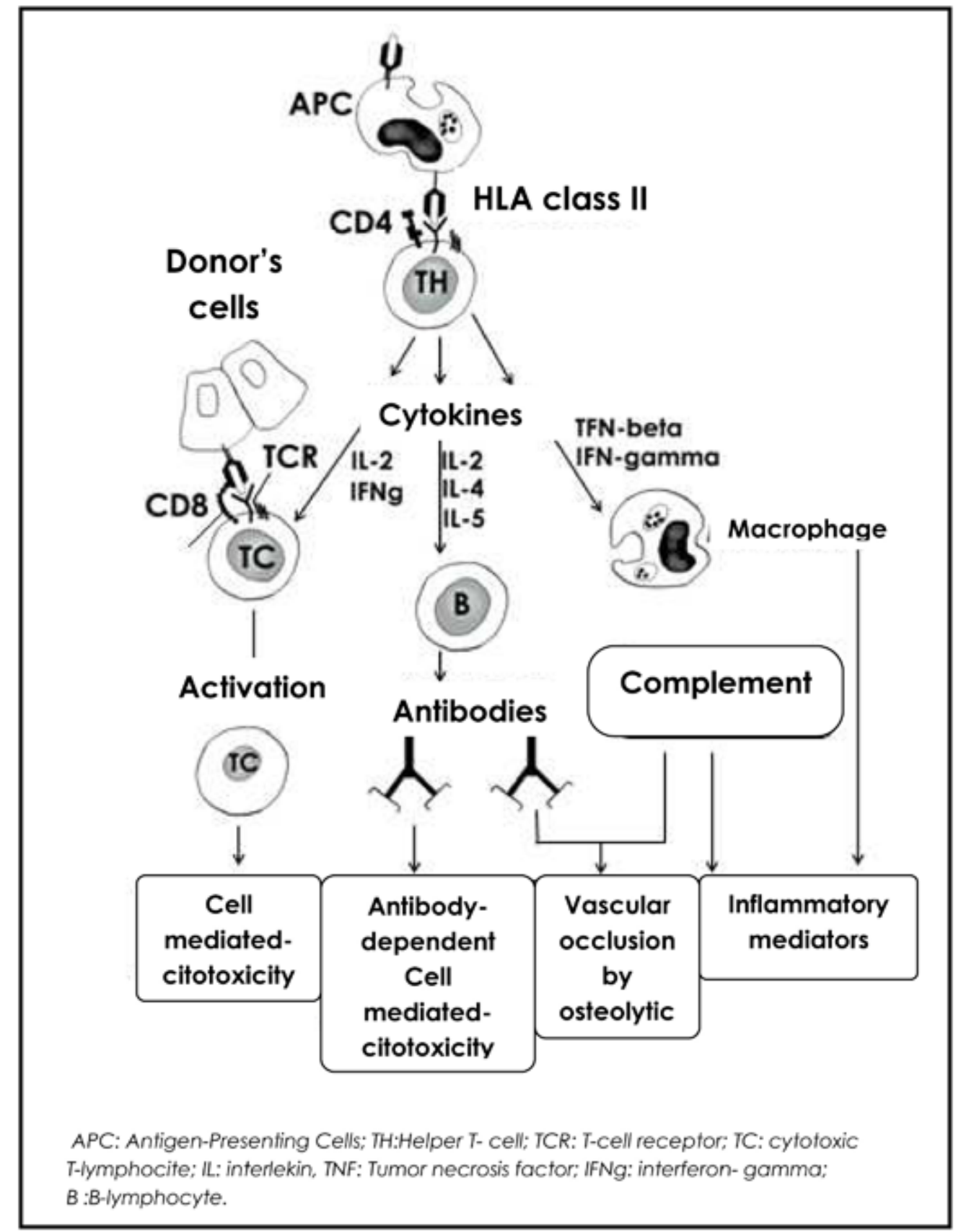

Figure 1. Helper T cells are activated to recognize antigen presented by the APCs. The activation releases cyotokines that are mediators of different mechanisms of rejection. 
jection. Depending on the intensity, graft rejection can be: hyperacute, acute (Figure 2) or chronic. For the immunological study, the following tests have been performed: $\mathrm{ABO}$ blood group of the donor and recipient, HLA type determination of the donor and recipient, humoral sensitization to HLA antigens and a cross matching test (3).

Transplant patients are treated with immunosuppressive drugs for the rest of their lives. The drugs most used are: cyclosporine, azathioprine and tacrolimus commonly associated with glucocorticoids (prednisone). The aim of the use of these drugs is to prevent acute rejection, to allow the acceptance of the transplanted organ and to preserve the patient's immunity with the least possible alteration. Due to immunosuppressive therapy that these patients are submitted to there may be oral impact and clinical manifestations can appear that we should consi$\operatorname{der}(1,4,5)$.

\section{Objectives}

The aim of this article was to perform a literature review about:

1. Oral manifestations in transplant patients.

2. General dental management: before and after transplants.

3. Special dental management according to transplant organs: heart, lung, liver, kidney, pancreas and bone marrow.

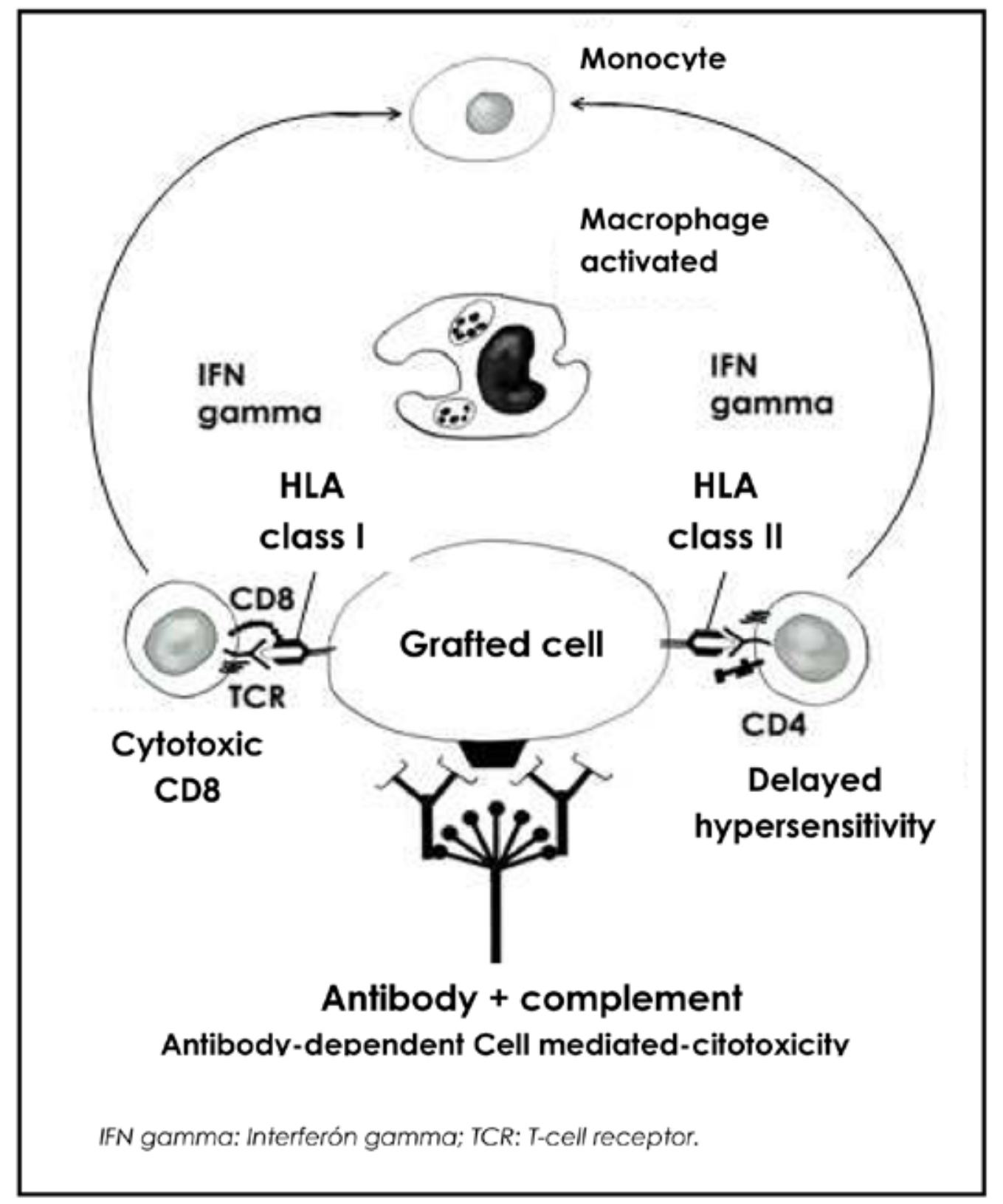

Figure 2. Immunological mechanism of acute rejection. 


\section{Materials and method}

For the literature review, we carried out a literature search in Pubmed / Medline database using the following words according to the controlled vocabulary (MeSH): "dental management", "oral manifestations", "transplant patients", "cardiac transplant", "lung transplant", "heart-lung transplant", "liver transplant", "renal transplant", "kidney transplant", "pancreas transplant”, "hematopoietic stem cell transplant”. The limits used for the search were: articles in english or spanish and articles published within the last 15 years. We reviewed a total of 30 articles (eight literature reviews, three randomized clinical trials, one cohort study, three case-control studies, eight clinical case series and seven cross-sectional studies).

\section{Results}

\section{Oral manifestations in transplant patients}

As a result of the long term immunosuppressive therapy that these patients are submitted to, their immune response is reduced, which it makes them more susceptible to develop infections; fungal infection has the highest degree of mortality rate despite its lower incidence compared to bacterial and viral infections. There is an increased prevalence of oral candidiasis and the cause is usually the species Candida albicans, although an increased prevalence of infections caused by other species (Candida krusei, Candida tropicalis and Candida glabrata) has been observed. Cytomegalovirus infection (CMV) is common in the first months after transplant. The herpes simplex virus and varicella-Zoster have also been observed in these patients. In addition, prolonged immunosuppression makes them more vulnerable to human herpesvirus-8. Several studies refer to the discovery of hairy leukoplakia lesions in these groups of patients, which is associated with Epstein-Barr virus (1,5-18).

Another side effect of the use of cyclosporine is gingival hyperplasia. It usually affects the facial surfaces of the interdental papilla and it may appear on gingival margins and lingual surfaces. It interferes with the patient's oral hygiene leading to an increased susceptibility to infections, caries and periodontal disease $(5,7-11,19)$.

It has been shown that after transplant there is an increased risk of malignant oral lesions. A greater predisposition to epithelial dysplasia and carcinoma of the lip has been observed. There have been several cases of squamous cell carcinoma and Kaposi's sarcoma in areas of gingival hyperplasia induced by treatment with cyclosporine. In addition, several studies such as DíazOrtiz et al. (2) relate xerostomia after the transplant $(1,5,7,9,13)$.

General dental management in transplant patients

Before performing any transplant we must consider general dental management (Table 1):

- A consultation with the physician is recommended to discuss overall condition of the patient (1-5).

- We must educate, inform and motivate the patient to maintain a proper oral hygiene and to be aware of the risk and problems that may arise in the oral cavity after transplant. We must give oral hygiene instructions and recommend the use of fluorinated compounds and antiseptic mouthwashes such as chlorhexidine $(1,2,5,19-21)$.

- Dental status should be evaluated. For dental treatment planning, we must carry out a radiographic study. The main objectives of dental treatment are $(1,2,5,21)$ :

-To maintain adequate periodontal health. We must remove supra- and subgingival plaque with dental scaling and curettage.

- Filling of teeth with caries with favorable prognosis.

- Endodontic treatments.

- Implant treatment must be postponed until the stable period of the transplant and when the patient's condition has improved. If it is possible to carry out implant treatment before transplant, we must perform this with sufficient time to evaluate the biological response of the abutments teeth or the osseointegration of the implants.

- Extraction of teeth with poor prognosis or uncertain prognosis, periodontally compromised teeth with deeper pockets than 5-6 mm, teeth with furcation involvement or endoperiodontal lesions, teeth with periapical lesions and teeth with a root canal are technically difficult or with uncertain prognosis and teeth with very deep or extensive caries.

- The therapeutic approaches for the control of gingival hyperplasia in patients receiving cyclosporine are $(2,4,10,22)$ :

- Various authors, such as Ciavarella et al. (10) have shown that reducing the dose of cyclosporine or substituting it with another immunosuppressant such tacrolimus, rifampicin or mycophenolate mofetil improves gingival hyperplasia. However, the nature of the transplanted organ does not often allow the replacement or reduction of the dose. In this case, the treatment is based on the prevention and elimination of predisposing factors.

- It had been demonstrated that oral hygiene can reduce the degree of gingival hyperplasia by reducing the inflammatory component which has produced the plaque but does not inhibit their development.

- The need for surgical treatment should be carefully considered as it is carried out for cosmetic and aesthetic reasons.

- Patients who have been treated with corticosteroids for a long time or in stressful situations may require supplementation of corticosteroids to prevent adrenal 
General dental management BEFORE transplant

1. A consultation with the physician is recommended to discuss overall condition of the patient.

2. We must give oral hygiene instructions and recommend the use of fluorinated compounds and antiseptic mouthwashes such as chlorhexidine.

3. Dental status should be evaluated. For dental treatment planning, we must carry out a radiographic study. The main objectives of dental treatment are:

- To maintain adequate periodontal health. We must remove supra- and subgingival plaque with dental scaling and curettage.

- Filling of teeth with caries with favorable prognosis.

- Extraction of teeth with poor prognosis or uncertain prognosis, periodontally compromised teeth with deeper pockets than 5-6 mm, teeth with furcation involvement or endoperiodontal lesions, teeth with periapical lesions and teeth with a root canal are technically difficult or with uncertain prognosis and teeth with very deep or extensive caries.

- Endodontic treatments.

- Implants treatment must be postponed until the stable period of the transplant and when patient's condition has improved.

4. Control of gingival hyperplasia in patients receiving cyclosporine.

5. Patients who have been treated with corticosteroids for a long time or in stressful situations may require supplementation before dental treatment.

6. We must be careful with the use of certain drugs $(1,5)$ :

- General anesthesia,

- Nonsteroidal anti-inflammatory drugs (NSAIDs),

- Aspirin,

- Antibiotics (erythromycin, clarithromycin, tetracyclines, aminoglycosides and quinolones),

- Azole antifungals (ketoconazole, fluconazole and itraconazole),

- Co-trimoxazole.

Table 1. General dental management before transplant.

crisis (Table 2 and 3 ). We also recommend morning appointments, a quiet working environment and to avoid sudden and unexpected movements during dental treatment $(1,9,13)$.

- We must be careful with the use of certain drugs $(1,5)$ :

- General anesthesia.

- Nonsteroidal anti-inflammatory drugs (NSAIDs): these drugs enhance the nephrotoxicity of cyclosporine and tacrolimus and may increase bleeding and exacerbate peptic ulcer disease in patients treated with corticosteroids.
- Aspirin increases the risk of bleeding.

- Antibiotics (erythromycin and clarithromycin), azole antifungals (ketoconazole, fluconazole and itraconazole) and NSAIDs can alter the levels of cyclosporine and consequently there is an increase in serum levels, rendering patients with a greater immnosuppresion than we desire.

- Co-trimoxazole, tetracyclines, aminoglycosides and quinolones increase risk of nephrotoxicity.

After organ transplant has been carried out, we must consider several aspects (Table 4); the period of time after transplant can be divided into:

\begin{tabular}{|l|c|c|}
\hline \multicolumn{2}{|c|}{ A CONSERVATIVE dental procedure } \\
\hline Patient's situation & & Therapeutic approach \\
\hline Present corticoid use & $\begin{array}{c}\text { Low-dose corticotherapy }(< \\
30 \mathrm{mg} \text { of hydrocortisone/day) }\end{array}$ & No supplementing required \\
\hline \multirow{4}{*}{ Regular corticoid use } & $\begin{array}{c}\text { High-dose corticotherapy for a } \\
\text { month if the patient has discon- } \\
\text { tinued use less than two weeks } \\
\text { ago }\end{array}$ & $\begin{array}{c}\text { Daily maintenance dose on the day } \\
\text { of treatment }\end{array}$ \\
\cline { 2 - 3 } & $\begin{array}{c}\text { High-dose corticotherapy for } \\
\text { more than a month }\end{array}$ & No established regimen \\
\hline If less than one month with discontinued treatment with corticosteroids & No supplementing required \\
\hline
\end{tabular}

Table 2. Corticosteroid supplementation with a conservative dental procedure. 


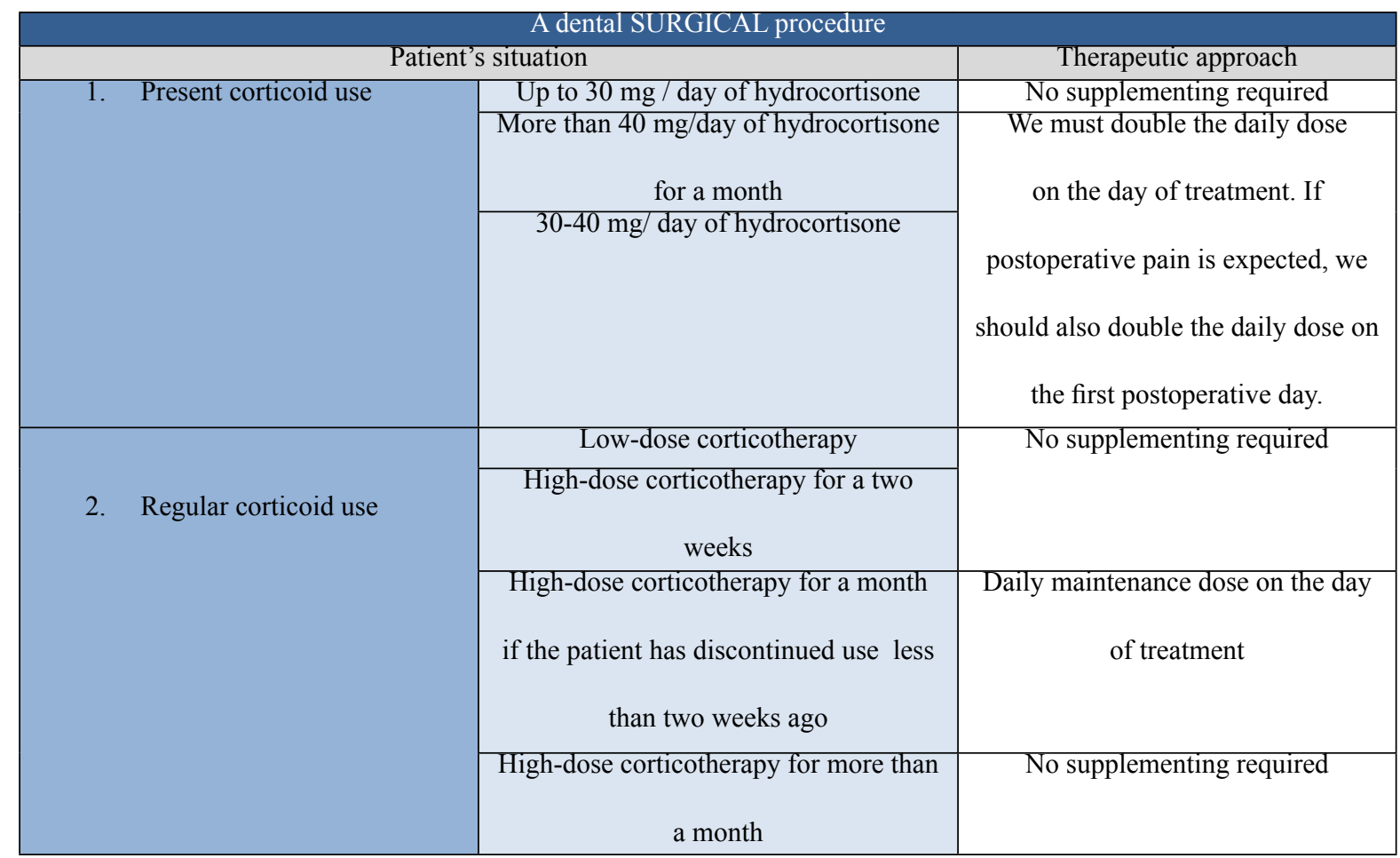

Table 3. Corticosteroid supplementation with a dental surgical procedure.

\begin{tabular}{|c|c|}
\hline \multicolumn{2}{|r|}{ General dental management AFTER transplant } \\
\hline Period of time & Dental management \\
\hline $\begin{array}{l}\text { Immediate (first } \\
\text { three months after }\end{array}$ & $\begin{array}{l}\text { - It is recommended that emergency dental treatment be carried out in a hospital, and that } \\
\text { - The dentalist be consulted and treated with antibiotic prophylaxis. } \\
\text { - } \quad \text { Prevent hyposalivation and xerostomía: mouthrinses with } 0.5 \% \text { of aqueous } \\
\text { solution of sodium carboxy cellulose, every two hours. } \\
\text { - } \quad \text { Educate the patient about oral higiene: use of very soft toothbrush, fluoride } \\
\text { - } \quad \text { Eliminate risk factors and improve the diet. } \\
\text { - } \quad \text { Remove dentures and orthodontic appliances. } \\
\text { - Dental examination by the risk of developing malignant lesions. } \\
\text { - } \quad \text { Prevention of infections. }\end{array}$ \\
\hline Stable & $\begin{array}{l}\text { - After three months after transplant, elective dental treatment can be performed. } \\
\text { - Six months after transplant is the best time considered for dental treatment. } \\
\text { - If invasive dental treatment is necessary, we must give prophylactic antibiotic and } \\
\text { a complete blood count is recommended. }\end{array}$ \\
\hline $\begin{array}{l}\text { 3. Transplant } \\
\text { rejection: (acute or } \\
\text { chronic) }\end{array}$ & $\begin{array}{l}\text { - Dental treatment should be postponed. } \\
\text { - Only emergency dental treatment should be performed. } \\
\text { - Prophylactic treatment with antibiotics may be useful to prevent sepsis. }\end{array}$ \\
\hline
\end{tabular}

Table 4. General dental management after transplant. 
1. Immediate (first three months after surgery): this is the maximum life-threatening period, so it is recommended that emergency dental treatment be carried out in a hospital, and that specialist be consulted and treated with antibiotic prophylaxis. The dental treatment will be essentially palliative and local $(1,5,9,21)$, the aim is to:

- Prevent hyposalivation and xerostomia (mouthrinses with $0.5 \%$ of aqueous solution of sodium carboxy cellulose, every two hours).

- Educate the patient about oral hygiene (use of very soft toothbrush, fluoride toothpaste and antiseptic mouthrinses such as clorhexidine).

- Eliminate risk factors (cigarettes and alcohol) and improve the diet (soft diet, avoiding irritant, cariogenic or excessively hot foods.)

- Remove dentures and orthodontic appliances.

- Prevention of infections.

2. Stable (more than three months), when no signs of rejection have been observed. After three months after transplant, elective dental treatment can be performed. However, six months after transplant is the best time considered for dental treatment. If invasive dental treatment is necessary, we must give prophylactic antibiotic and a complete blood count is recommended, because the graft anastomosis has not completely epithelialized and the patient has a high level of immunosuppression $(1,5,9,21,23)$.

3. Transplant rejection: It may be acute or chronic. Acute rejection usually occurs during the first months and chronic rejection is often preceded by several episodes of acute rejection and usually occurs over a period of years (over 5 years). If this occurs, dental treatment should be postponed. Only emergency dental treatment should be performed. Prophylactic treatment with antibiotics may be useful to prevent sepsis $(1,21)$.

Special dental management according to transplanted organ

\section{Heart transplant}

The main causes of end-stage disease are idiopathic cardiomyopathy and end-stage coronary artery disease. The primary indication for heart transplant is end-stage heart failure. This can be the result of ischemic cardiomyopathy with intractable angina (1).

- Special dental management for heart transplant patients

- These patients are highly susceptible to hemorrhage due to neutropenia, anemia and thrombocytopenia. In many cases, patients can be treated with anticoagulants or antiplatelet drugs. We must take special care in dental treatment, a complete blood count is recommended including the International Normalized Ratio (INR), and apply the appropriate hemostatic measures such as the use of hemostatic agents (1).

- Anesthesia is recommended without vasoconstrictor because these patients may be more sensitive to epinephrine (1).

2. Lung transplant

Lung transplant is becoming a recommended treatment for patients with nonmalignant end-stage lung disease. One of the most common complications is infection. Pseudomonas aeruginosa is the most common bacterial pathogen, and cytomegalovirus is the most common viral infection in lung transplant patients $(1,24)$.

- Special dental management for lung transplant patients (1):

- Narcotic analgesics should not be considered because of their respiratory depression properties.

- These patients are usually on oxygen therapy. As a part of dental management, the use of any combustible products should be avoided.

3. Heart-lung transplant

Combined heart-lung transplants are performed in cases of pulmonary hypertension with right side heart failure and Eisenmenger's syndrome. The other indications are multi-organ end-stage disease, congenital abnormalities and amyloidosis, and simultaneous end-stage heart and lung disease $(1,25)$.

- Special dental management for heart-lung transplant patients

- We will perform the same management as in heart and lung transplant for prevention, treatment and prophylactic antibiotic therapy.

- We must control the appearance of malignancies because of its high risk of incidence (4.6\%) (1).

\section{Liver transplant}

Liver transplant is an option for treatment of many different disease conditions, though the most common indications are chronic liver disorders (biliary and nonbiliary cirrhosis), hepatocellular carcinoma and severe acute hepatic failure. In Spain, the most frequent indication according to the National Transplant Organization is cirrhosis secondary to hepatitis $\mathrm{C}$ virus (HCV) infection, followed by alcoholic cirrhosis $(1,2,5,23)$.

In a study performed by Díaz-Ortiz et al. (2) in liver transplant patients (53 patients), the most frequent oral manifestations were gingival hyperplasia, xerostomia, candidiasis and hairy leukoplakia.

Also, it showed a high prevalence of tongue pathology in these patients, particulary fissured tongue, saburral tongue, depapillated tongue, hairy tongue and geographical tongue. It should be taken into account that while these disorders are generally asymptomatic, they sometimes may also present candida overinfection and produce symptoms. Other factors such as oral environmental $\mathrm{pH}$ variations, xerostomia, vitamin $\mathrm{A}$ and $\mathrm{C}$ and/or calcium deficiencies, or some type of anemia have also been implicated (2).

We must take special care with patients with end-stage liver disease as they may frequently experience spon- 
taneous gingival bleeding and we must be careful with patients with alcoholic cirrhosis because they often have nutritional deficiencies manifesting with the appearance of petechiae, ecchymosis, angular cheilitis and glossitis with the presence of malignant lesions. It is also common to find sialadenosis (1).

- Special dental management for liver transplant patients

\section{Before liver transplant}

- In patients with liver failure who are undergoing liver transplant, we should be especially careful with drugs that are metabolized in the liver $(1,21)$ :

1. Local anesthetics (lidocaine, prilocaine, mepivacaine and bupivacaine) can be used safely when the total dose of $7 \mathrm{mg} / \mathrm{kg}$ is not exceeded and when combined with epinephrine.

2. Analgesics: paracetamol should not be used on a chronic basis (no more than two weeks) and must not exceed $4 \mathrm{~g}$. daily. Ibuprofen and aspirin should be avoided because they have a significant hepatic metabolism. It is preferable to use morphine as a narcotic analgesic rather than meperidine and codeine, because morphine has extra-hepatic metabolism.

3. Antibiotics (clindamycin, metronidazole and vancomycin): instead of these antibiotics we should use beta-lactam antibiotics.

4. Sedatives (diazepam, lorazepam and midazolam): these drugs can be used safely if we reduce the dose and if we increase dosing intervals between medications.

Although at present, there is no guide for modifying dosing intervals of these drugs in transplant patients and we should always consult the specialist $(1,10)$.

- Patients with liver failure often have abnormalities of coagulation factors, so there is an increased risk of bleeding with any invasive procedure. Before treatment, a complete blood count is recommended, including platelet count, INR, aspartate aminotransferase and alanine aminotransferase. If the platelet count is less than $50.000 / \mathrm{mm} 3$ the patient should be transfused with fresh plasma. After treatment, we must take all necessary local hemostatic measures $(1,21)$.

After liver transplant

- We must use drugs that are metabolized by the liver with caution.

5. Kidney transplant

A kidney transplant is now the treatment of choice for patients with end-stage renal disease. The most common cause of death in these patients is cardiovascular disease and not renal failure, although this is also a complication that can occur after transplant $(1,6,7,9,11-13,18,26)$.

- Special dental management for kidney transplant patients

Before kidney transplant
- We must be careful with the use of some drugs in patients with end-stage renal disease because as renal function is reduced, the plasma levels of some drugs may be high or prolonged $(1,13)$.

- Acetaminophen and codeine can be given for postoperative pain management (1).

- Local anesthetics are metabolized in the liver and hence are safe to use for dental procedures (1).

\section{Pancreas transplant}

Pancreas transplant can be carried out in conjunction with kidney transplant, after kidney transplant, or as a pancreas transplant alone. The simultaneous kidney and pancreas transplant is the most common type of pancreas transplant carried out, representing almost $78 \%$ of pancreas transplants carried out, and transplant of the pancreas alone is generally less than $5 \%(1,27)$.

- Special dental management for pancreas transplant patients

Before pancreas transplant

- The patients usually have significant glucose-management problems and hence their glucose levels should be considered before treatment.

7. Hematopoietic cell transplant

Hematopoietic cell transplant serves as a rescue procedure to reconstitute the hematopoietic system when damaged by high-dose chemo/radiotherapy for treatment of malignancy. Also it is used as an alternative therapy for other diseases, especially hematopoietic malignancies such as acute leukemia, multiple myeloma or nonHodgkin lymphoma. 2-7 days before hematopoietic cell transplant, the patient undergoes a preparative regimen consisting of high-dose chemotherapy, irradiation or both to accomplish total tumor kill, and to achieve a high state of immunosuppression. Then, hematopoietic cell transplant is carried out. It consists of infusion of donor stem cells through a central venous catheter and the patient is kept isolated for 30-60 days to prevent opportunistic infections and to evaluate the graft acceptance $(20,28-30)$.

The most common oral complications after hematopoietic cell transplant are:

1. Mucositis: it is the most frequent oral complication and it occurs by direct action of chemo/radiotherapy on mucosal progenitor cells. The World Health Organization classifies mucositis in 5 degrees ranging from mild erythema to severe mucosal ulcerative breakdown. Severe ulcerations can cause intense pain that interferes with eating or drinking. Mucositis becomes clinically evident shortly after transplant and peaks five to seven days post-transplant and will resolve spontaneously approximately 15-22 days after transplant $(28,29)$.

2. Risk of infection (29).

3. Oral bleeding: it can occur in patients with thrombocytopenia due to acute leukemia or secondary to a myelosuppression induced by the chemotherapy (29). 
4. Graft versus host disease (GVHD) is a reaction that arises because immunocompetent lymphocytes from donor's bone marrow release cytokines that react against recipient's antigens, which have a different degree of histocompatibility of the donor, causing damage in tissues and organs. It is a major cause of morbidity and mortality in patients with hematopoietic cell transplant. It distinguishes between acute if it occurs in a period less than 100 days from the infusion of stem cells and chronic if the period is longer than 100 days. Oral manifestations of the acute GVHD include xerostomia, mucosal lichenoid, papular lesions, erythema, atrophy and ulceration. Chronic GVHD affects the oral cavity in $80 \%$ of cases. Oral effects of chronic GVHD include mucosal erythema, tongue-surface atrophy, lichenoid changes of the buccal mucosa, ulcers and an increased incidence of oral cancer in the form of squamous cell carcinoma $(28,29)$.

6. Salivary changes and xerostomia: clinical manifestations include parotitis, increasingly mucinous saliva and decreased salivary flow. These features may persist for a year after transplant. Full recovery of salivary gland function in a two to five month period has been observed in patients receiving only chemotherapy or total lymphoid irradiation (avoiding parotid glands). Unfortunately, patients who have received significant radiation to their salivary glands or develop GVHD can experience chronic persistent of hypofunction of the salivary gland $(28,29)$.

\section{- Special dental management for hematopoietic cell} transplant patients

Before hematopoietic cell transplant

- Treatment of mucositis $(1,29)$.

After hematopoietic cell transplant

- To review oral cavity in search of any oral complication (GVHD) (29).

\section{Discussion}

1. The most common oral manifestations in transplant patients are: viral, bacterial and fungal infections, gingival hiperplasia due to cyclosporin and higher risk in developing oral malignancy.

2. General dental management in transplant patients:

- Before transplant: A consultation with the physician is recommended. We must educate the patient to maintain a proper oral hygiene. We must be careful with the use of certain drugs. Dental status should be evaluated and we must carry out a radiographic study.

- After transplant: in the first three months after transplant, it is recommended that we only carry out emergency dental treatment in a hospital. After three months, elective dental treatment can be performed. Six months after transplant is the best time considered for dental treatment. In case of rejection, only emergency dental treatment is recommended.
3. Specific dental management in transplant patients:

- Heart transplant: we must use local anesthesia without vasoconstrictor.

- Lung transplant: we must avoid narcotic analgesics.

- Heart-lung transplant: we must control the appearance of malignancies.

- Liver transplant: We must use drugs that are metabolized by the liver with caution.

- Kidney transplant: we must use with caution drugs with renal elimination.

- Pancreas transplant: we must evaluate levels of glucose in the blood.

- Hematopoietic cell transplant: we must treat mucositis and control GHVD.

\section{References}

1. Vasanthan A, Dallal N. Periodontal treatment considerations for cell transplant and organ transplant patients. Periodontol 2000. 2007;44:82102.

2. Díaz-Ortiz ML, Micó-Llorens JM, Gargallo-Albiol J, Baliellas-Comellas C, Berini-Aytés L, Gay-Escoda C. Dental health in liver transplant patients. Med Oral Patol Oral Cir Bucal. 2005 ;10:66-72.

3. Neumann UP, Guckelberger O, Langrehr JM, Lang M, Schmitz V, Theruvath $\mathrm{T}$, et al. Impact of human leukocyte antigen matching in liver transplantation. Transplantation. 2003;75:132-7.

4. Khoori AH, Einollahi B, Ansari G, Moozeh MB. The effect of cyclosporine with and without nifedipine on gingival overgrowth in renal transplant patients. J Can Dent Assoc. 2003;69:236-41.

5. Guggenheimer J, Eghtesad B, Stock DJ. Dental management of the (solid) organ transplant patient. Oral Surg Oral Med Oral Pathol Oral Radiol Endod. 2003;95:383-9.

6. Al-Mohaya MA, Darwazeh A, Al-Khudair W. Oral fungal colonization and oral candidiasis in renal transplant patients: the relationship to Miswak use. Oral Surg Oral Med Oral Pathol Oral Radiol Endod. 2002;9:455-60.

7. Al-Mohaya MA, Darwazeh AM, Bin-Salih S, Al-Khudair W. Oral lesions in Saudi renal transplant patients. Saudi J Kidney Dis Transpl. 2009;20:20-9.

8. Nowzari H, Jorgensen MG, Aswad S, Khan N, Osorio E, Safarian A, et al. Human cytomegalovirus-associated periodontitis in renal transplant patients. Transplant Proc. 2003;35:2949-52.

9. Jover Cerveró A, Bagán JV, Jiménez Soriano Y, Poveda Roda R. Dental management in renal failure: patients on dialysis. Med Oral Patol Oral Cir Bucal. 2008;1:E419-26.

10. Ciavarella D, Guiglia R, Campisi G, Di Cosola M, Di Liberto C, Sabatucci A, et al. Update on gingival overgrowth by cyclosporine A in renal transplants. Med Oral Patol Oral Cir Bucal. 2007;12:E19-25.

11. de la Rosa-García E, Mondragón-Padilla A, Irigoyen-Camacho ME, Bustamante-Ramírez MA. Oral lesions in a group of kidney transplant patients. Med Oral Patol Oral Cir Bucal. 2005;10:196-204. 12. Braz-Silva PH, Ortega KL, Rezende NP, Nunes FD, Magalhães $\mathrm{MH}$. Detection of Epstein-Barr virus (EBV) in the oral mucosa of renal transplant patients. Diagn Cytopathol.2006;34:24-8.

13. Proctor R, Kumar N, Stein A, Moles D, Porter S. Oral and dental aspects of chronic renal failure. J Dent Res. 2005;84:199-208.

14. Cubiella J, Sala M, Fernández J, Navasa M, Salmerón J, Gómez $\mathrm{J}$, et al. Infectious complications associated with liver transplantation: analysis of 104 patients. Gastroenterol Hepatol. 2001;24:186-90.

15. Nampoory MR, Khan ZU, Johny KV, Constandi JN, Gupta RK, Al-Muzairi I, et al. Invasive fungal infections in renal transplant recipients. J Infect. 1996;33:95-101.

16. Epstein JB, Gorsky M, Caldwell J. Fluconazole mouthrinses for oral candidiasis in postirradiation, transplant, and other patients. Oral Surg Oral Med Oral Pathol Oral Radiol Endod. 2002;93:671-5.

17. Kaufman DB, Leventhal JR, Gallon LG, Parker MA, Koffron AJ, 
Fryer JP, et al. Risk factors and impact of cytomegalovirus disease in simultaneous pancreas-kidney transplantation. Transplantation. 2001;72:1940-5.

18. Batiuk TD, Bodziak KA, Goldman M. Infectious disease prophylaxis in renal transplant patients: a survey of US transplant centers. Clin Transplant. 2002;16:1-8

19. Párraga-Linares L, Almendros-Marqués N, Berini-Aytés L, GayEscoda C. Effectiveness of substituting cyclosporin A with tacrolimus in reducing gingival overgrowth in renal transplant patients. Med Oral Patol Oral Cir Bucal. 2009;14:e429-33.

20. Epstein J.B, Hancock P.J, Nantel S. Oral candidiasis in hematopoietic cell transplantation patients: an outcome-based analysis. Oral Surg Oral Med Oral Pathol Oral Radiol Endod. 2003;96:154-63.

21. Douglas LR, Douglass JB, Sieck JO, Smith PJ. Oral management of the patient with end-stage liver disease and the liver transplant patient. Oral Surg Oral Med Oral Pathol Oral Radiol Endod. 1998;86:5564.

22. Oettinger-Barak O, Barak S, Machtei EE, Ardekian L, Baruch Y, Peled M. Periodontal changes in liver cirrhosis and post-transplantation patients. I: clinical findings. J Periodontol. 2001;72:1236-40.

23. Guggenheimer J, Mayher D, Eghtesad B. A survey of dental care protocols among US organ transplant centers. Clin Transplant. 2005; $19: 15-8$

24. Rutherford RM, Fisher AJ, Hilton C, Forty J, Hasan A, Gould FK, et al. Functional status and quality of life in patients surviving 10 years after lung transplantation. Am J Transplant. 2005;5:1099-104.

25. Reichart B, Gulbins H, Meiser BM, Kur F, Briegel J, Reichenspurner $\mathrm{H}$. Improved results after heart-lung transplantation: a 17-year experience. Transplantation. 2003;75:127-32.

26. Campo A. Chronic renal failure after transplantation of a nonrenal organ. N Engl J Med. 2003;349:931-40.

27. Arjona A, Martínez-Cecilia D, Ruiz-Rabelo JF, Muñoz F, López M, Agüera M, et al. One hundred one simultaneous pancreas-kidney transplantations: long-term outcomes at a single center. Transplant Proc. 2009;41:2463-5.

28. Westbrook SD, Paunovich ED, Freytes CO. Adult hemopoietic stem cell transplantation. J Am Dent Assoc. 2003;134:1224-31.

29. Epstein JB, Raber-Drulacher JE, Wilkins A, Chavarria MG, Myint $\mathrm{H}$. Advances in hematologic stem cell transplant: an update for oral health care providers. Oral Surg Oral Med Oral Pathol Oral Radiol Endod. 2009;107:301-12.

30. Guimaraes AL, Gomes CC, da Silva LM, Correia-Silva Jde F, Victoria JM, Gomez RS, et al. Association between oral HSV-1 and survival in allogeneic hematopoietic stem cell transplanted patients. Med Oral Patol Oral Cir Bucal. 2009;14:E62-8. 